\title{
Acute blood volume expansion delays the gastrointestinal transit of a charcoal meal in awake rats
}

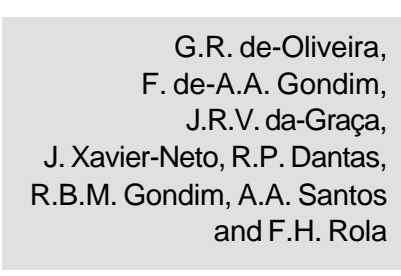

G.R. de-Oliveira,

F. de-A.A. Gondim,

to R.P. and F.H. Rola

\section{Correspondence}

F.H. Rola

Departamento de Fisiologia e

Farmacologia, UFC

Rua Coronel Nunes de Melo, 1127

Caixa Postal 3157

60430-270 Fortaleza, CE

Brasil

Fax: 55 (085) 243-9333

Presented at the 8th European Symposium on GI Motility,

Copenhagen, Denmark, June, 1996

and reported in abstract form

(Neurogastroenterology and

Motility (1996) 8: 168).

Research supported by CAPES,

CNPq, UNIMED and UFC.

.....................

Received February 14, 1997

Accepted March 17, 1998

.................
Departamento de Fisiologia e Farmacologia, Faculdade de Medicina, Universidade Federal do Ceará, Fortaleza, CE, Brasil

\section{Abstract}

The present study evaluates the effect of blood volume expansion on the gastrointestinal transit of a charchoal meal $(2.5 \mathrm{ml}$ of an aqueous suspension consisting of 5\% charcoal and 5\% gum arabic) in awake male Wistar rats (200-270 g). On the day before the experiments, the rats were anesthetized with ether, submitted to left jugular vein cannulation and fasted with water ad libitum until $2 \mathrm{~h}$ before the gastrointestinal transit measurement. Blood volume expansion by $i v$ infusion of $1 \mathrm{ml} / \mathrm{min}$ Ringer bicarbonate in volumes of 3, 4 or $5 \%$ body weight delayed gastrointestinal transit at $10 \mathrm{~min}$ after test meal administration by $21.3-26.7 \%(\mathrm{P}<0.05)$, but no effect was observed after 1 or $2 \%$ body weight expansion. The effect of blood volume expansion (up to $5 \%$ body weight) on gastrointestinal transit lasted for at least $60 \mathrm{~min}$ $(\mathrm{P}<0.05)$. Mean arterial pressure increased transiently and central venous pressure increased and hematocrit decreased $(\mathrm{P}<0.05)$. Subdiaphragmatic vagotomy and yohimbine $(3 \mathrm{mg} / \mathrm{kg})$ prevented the delay caused by expansion on gastrointestinal transit, while atropine (0.5 mg/kg), L-NAME (2 mg/kg), hexamethonium (10 mg/kg), prazo$\sin (1 \mathrm{mg} / \mathrm{kg})$ or propranolol $(2 \mathrm{mg} / \mathrm{kg})$ were ineffective. These data show that blood volume expansion delays the gastrointestinal transit of a charcoal meal and that vagal and yohimbine-sensitive pathways appear to be involved in this phenomenon. The delay in gastrointestinal transit observed here, taken together with the modifications of gastrointestinal permeability to salt and water reported by others, may be part of the mechanisms involved in liquid excess management.

\section{Introduction}

The gastrointestinal (GI) tract, besides carrying out its function of nutrient digestion and absorption/secretion, is vitally important in maintaining water, electrolyte and acid-base regulation $(1,2)$. Small intestine fluid absorption capacity in humans is about
Key words

- Hypervolemia

- Blood volume

- Gastrointestinal transit

- Rats

- Gastrointestinal motility 
intestinal fluid/electrolyte absorption and increases secretion (5) while intestinal water and sodium absorption increases during $\mathrm{BV}$ retraction (6). Hypervolemia may also increase uretero-pelvic pressure, which has been shown to decrease jejunal absorption (7). This reflex pattern has been considered to be important for the management of increased body fluid (7). Since GI motility is coupled to absorption and secretion (8), GI motility changes may be important for the management of liquid volume imbalances.

We have shown that BV changes modify the gastrointestinal tonus in anesthetized dogs: volume overload is followed by decreased gastric and jejunal compliances while bleeding increases them $(9,10)$. In a barostatically perfused system we have also observed, in anesthetized dogs and rats, that the resistance offered by the gastroduodenal (GD) segment to the flow of liquid is modulated by BV levels: BV expansion decreased the GD flow while $\mathrm{BV}$ retraction increased it $(11,12)$.

This evidence comes from experiments carried out on anesthetized animals after rather invasive surgical procedures. Searching for an experimental model that avoids the influence of anesthesia on the autonomic nervous system, in the present study we evaluated the effect of BV expansion on the GI transit of a charcoal meal in awake rats and the neural mechanisms involved in this process.

\section{Material and Methods}

\section{Surgical procedures}

On the day before the experiment, male Wistar rats $(\mathrm{N}=181,200-270 \mathrm{~g})$ were anesthetized with ether and a polyethylene catheter (PE 50) was inserted into the left external jugular vein. The catheter was passed under the skin and its free end fixed outside through a dorsal skin incision between the shoulders. The rats were fasted for $24 \mathrm{~h}$ but received water ad libitum until $2 \mathrm{~h}$ before the experiment. All surgical procedures and animal treatments were conducted in accordance with the "Guide for the Care and Use of Laboratory Animals", NIH, Bethesda, MD.

\section{GI transit measurement}

For GI transit measurements, we used a modification of the method reported by Green (13). First, $2.5 \mathrm{ml}$ of an aqueous suspension of $5 \%$ charcoal and $5 \%$ gum arabic was administered by gavage. After 10, 15, 30, 45 and $60 \mathrm{~min}$, the animals were sacrificed with an $i v$ thiopental overdose. The small intestine was removed after laparotomy, its length measured $(\mathrm{cm})$ from the pyloric sphincter to the ileocecal junction and the distance traveled by the front of the meal was recorded as percent of the small intestine length. Since the intestines of all animals were of quite similar length (mean $110.3 \pm 4.1 \mathrm{~cm}$ ), the GI transit index is defined as distance the marker traveled/total length of intestine $\mathrm{x} 100$ and is reported as \% at a specified time after receiving the test meal by gavage. Unless otherwise identified 10 min was used for GI transit measurement.

\section{Treatments and experimental design}

The animals were randomly assigned to one of the two following protocols: normovolemic control or BV expansion. Groups consisting of 5-8 animals were used for each subset of experiments. GI transit index was determined $10 \mathrm{~min}$ after receiving the test meal in normovolemic control animals and in animals previously submitted to an $i v$ infusion of Ringer bicarbonate $(140 \mathrm{mEq} / \mathrm{l}$ $\mathrm{Na}^{+}, 4 \mathrm{mEq} / 1 \mathrm{~K}^{+}, 124 \mathrm{mEq} / \mathrm{l} \mathrm{Cl}-20 \mathrm{mEq} / \mathrm{l}$ $\left.\mathrm{HCO}_{3}{ }^{-}\right)$, at the rate of $1 \mathrm{ml} / \mathrm{min}$ in volumes of $1,2,3,4$ or $5 \%$ body weight. GI transit was also determined 15, 30, 45 and 60 min after the test meal in normovolemic controls and in animals previously submitted to $5 \% \mathrm{BV}$ expansion. 


\section{Investigation of neural mechanisms}

Atropine sulfate $(0.5 \mathrm{mg} / \mathrm{kg}$; Sigma Chemical Co., St. Louis, MO), No-nitro-L-arginine methyl ester $(2 \mathrm{mg} / \mathrm{kg}$; L-NAME, Sigma), prazosin chloride (1 mg/kg; Pfizer, Guarulhos, SP, Brazil), yohimbine hydrochloride (3 mg/kg; Sigma), propranolol hydrochloride ( $2 \mathrm{mg} / \mathrm{kg}$; Sigma) or hexamethonium bromide (10 mg/kg; Sigma), were injected $i v$ for investigation of neural mechanisms. GI transit measurements were performed in drug controls or in animals submitted to $5 \% \mathrm{BV}$ expansion, after drug pretreatment. The time elapsed between drug pretreatment and test meal administration was 10 (prazosin, yohimbine, L-NAME) or $30 \mathrm{~min}$ (atropine, propranolol or hexamethonium). All animals were sacrificed $10 \mathrm{~min}$ after administration of the test meal.

In another group, submitted to a 6-h fasting period, a subdiaphragmatic vagotomy was performed $24 \mathrm{~h}$ prior to the experiments. A complete esophageal transection was performed $1 \mathrm{~cm}$ above the gastroesophageal junction and the esophageal lumen was reconstituted by inserting and fixing a $0.7-\mathrm{cm}$ plastic tube (0.4 cm ID) (14). Sham operation for this group consisted of laparotomy.

\section{Hemodynamic data}

In separate groups of 4-5 awake rats, mean arterial pressure (MAP) was monitored for $45 \mathrm{~min}$ before and after the submission to the different experimental treatments, including drug administration. For this purpose, a catheter was placed into the carotid artery and connected to a mercury $(\mathrm{Hg})$ manometer. Central venous pressure (CVP) was monitored in awake animals before and after $5 \% \mathrm{BV}$ expansion $(\mathrm{N}=5)$. A catheter was inserted into the right external jugular vein, positioned in the right atrium and connected to a low pressure transducer (Statham P23) which was connected to a Mark IV Physiograph (Narco Byo-Systems, Houston, TX).
Intracardiac blood samples from controls ( $\mathrm{N}$ $=5$ ) and animals submitted to 5\% BV expansion $(\mathrm{N}=5)$ were also collected for hematocrit $(\mathrm{Ht})$ determination after sacrifice.

\section{Statistical analysis}

The results are reported as mean \pm SEM. Descriptive statistics were applied to each group of experiments. One-way analysis of variance and the Student-Newman-Keuls test were used to compare the various groups. Differences were considered significant at $\mathrm{P}<0.05$.

\section{Results}

Figure 1 shows the effect of BV expansion on the GI transit of a charcoal meal when measured $10 \mathrm{~min}$ after test meal administration. BV expansion up to 1 and $2 \%$ body weight caused a slight but nonsignificant decrease in GI transit rates while BV expansion of 3,4 and $5 \%$ body weight significantly decreased GI transit $(\mathrm{P}<0.05)$. Figure 2 shows that GI transit rates were decreased for at least $60 \mathrm{~min}$ after 5\% BV expansion $(\mathrm{P}<0.05)$.

Table 1 shows GI transit rates in drugpretreated or vagotomized animals submitted or not (drug controls) to 5\% BV expansion. As can be seen, either subdiaphragmatic vagotomy or yohimbine prevented the effect of BV expansion on GI transit (Figure

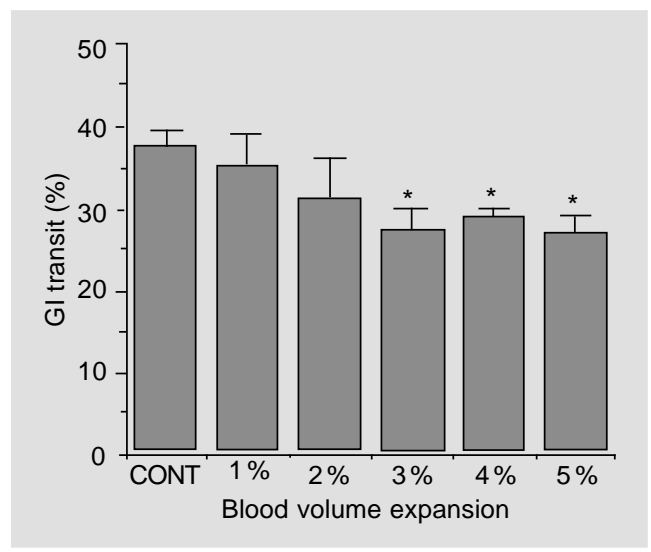

Figure 1 - Effect of acute blood volume expansion on gas trointestinal (GI) transit rates, 10 min after intragastric administration of a charcoal meal $(2.5$ $\mathrm{ml}$ of an aqueous suspension of $5 \%$ charcoal and $5 \%$ gum arabic) to controls (CONT; $N=6$ ) and animals submitted to blood volume expansion by iv infusion of Ringer-bicarbonate, $1 \mathrm{ml} / \mathrm{min}$, in volumes of $1,2,3,4$ and $5 \%$ body weight $(\mathrm{N}=5,5,5,5$ and 6 , respectively). ${ }^{*} \mathrm{P}<0.05 \mathrm{com}$ pared to control (StudentNewman-Keuls test). 
Figure 2 - Comparison of gastrointestinal (GI) transit rates of an aqueous charcoal meal $(2.5$ $\mathrm{ml}$ of an aqueous suspension of $5 \%$ charcoal and $5 \%$ gum arabic) in controls (CONT; $\mathrm{N}=6,5$, 7,6 and 6 , respectively) and in animals submitted to $5 \%$ blood volume expansion (EXP; $\mathrm{N}=5$, $5,8,7$, and 6 , respectively) by iv infusion of Ringer-bicarbonate, $1 \mathrm{ml} / \mathrm{min}, 10,15,30,45$ and 60 min after the intragastric test meal administration. ${ }^{*} \mathrm{P}<0.05$ compared to control (StudentNewman-Keuls test).

Figure 3 - Effect of subdiaphragmatic vagotomy (VAG) and yohimbine $(\mathrm{YOH})$ administration (3 $\mathrm{mg} / \mathrm{kg}$ ) on gastrointestinal (Gl) transit delay of an aqueous charcoal meal due to $5 \%$ blood volume (BV) expansion (EXP) by iv infusion of Ringer-bicarbonate, $1 \mathrm{ml} / \mathrm{min}$ in awake rats. VAG and $V A G+E X P$ refer to vagotomized animals submitted or not to BV expansion ( $\mathrm{N}=5$ in each group) and $\mathrm{YOH}$ and $\mathrm{YOH}+\mathrm{EXP}$ to yohimbine-pretreated animals submitted or not to BV expansion ( $N=5$ in each group). NS, Not significant (Student-NewmanKeuls test).
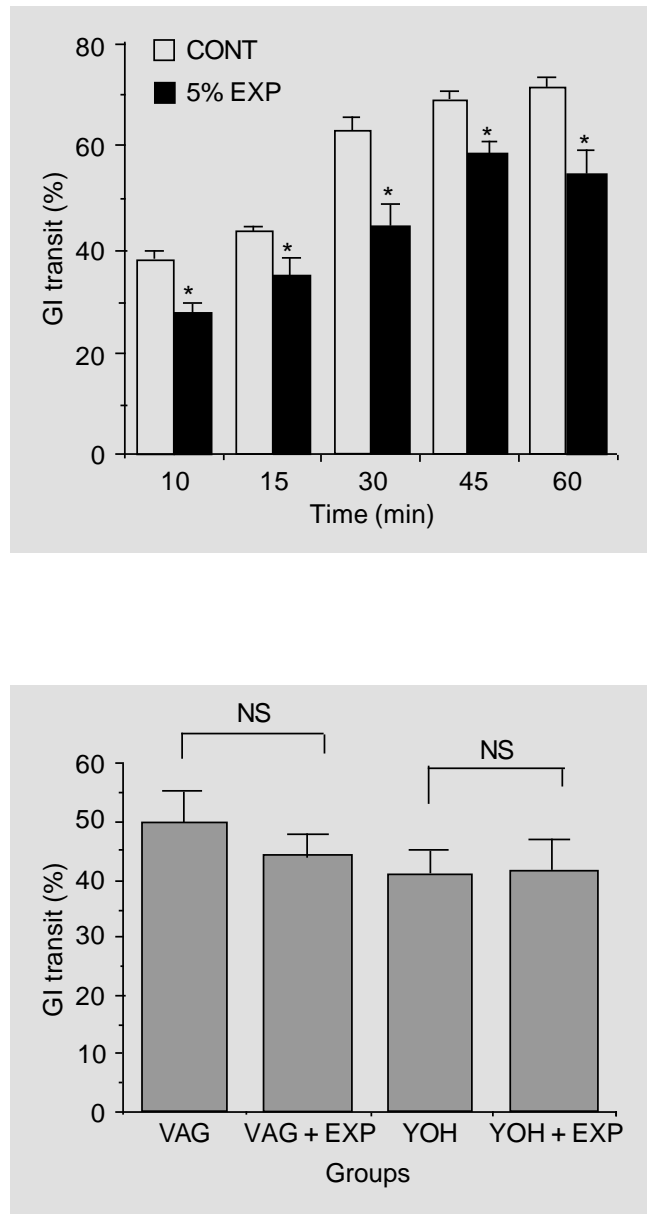

3). Despite preventing the BV expansion effect on GI transit, we still observed a trend for a decrease in GI transit after BV expansion in vagotomized animals, which however was not statistically significant. Hexamethonium, atropine, L-NAME, prazosin or propranolol pretreatments, however, were ineffective (Table 1).

BV expansion (5\%) transiently increased MAP during the expansion period (from $108.2 \pm 3.2$ to $119.7 \pm 4.1, \mathrm{P}<0.05, \mathrm{~N}=5$ ). However, MAP levels were not significantly modified after expansion was completed (expanded period, $116.1 \pm 3.1$ ). Table 2 shows that atropine and yohimbine decreased MAP. L-NAME increased while hexamethonium, propranolol and prazosin significantly decreased MAP values $(\mathrm{P}<0.05)$. BV expansion also increased CVP values (from $3.6 \pm$ 1.6 to $9.6 \pm 3.2 \mathrm{cmH}_{2} \mathrm{O}, \mathrm{P}<0.05, \mathrm{~N}=5$ ) while decreasing the mean hematocrit (from $49.6 \pm$ 1.6 to $34 \pm 1.1, \mathrm{P}<0.05, \mathrm{~N}=5$ ).

\section{Discussion}

We have observed that acute BV changes modify the GI motility in anesthetized rats and dogs: gastric and jejunal compliance $(9,10)$, as well as the resistance offered by the gastroduodenal segment to the flow of liquid $(11,12)$. We have also recently extended these observations to the ileocolonic region (15). The present study, which has been reported in abstract form (16), extend these observations from anesthetized to awake rats, avoiding the interference of anesthesia on the autonomic nervous activity. Furthermore, we evaluated the relationship between the volume infused and the GI transit delay and studied the neural mechanisms involved in this phenomenon.

The results show that BV expansion delays the GI transit of an aqueous charcoal meal in awake rats. BV expansion of 1 and $2 \%$ body weight had no significant effect on GI transit but BV expansion of 3, 4 and 5\% body weight significantly decreased GI tran- 
sit rates. This effect persisted for at least 60 min after expansion of $5 \%$ body weight.

The factors that influence the rate of propulsion of a meal through the small intestine are not completely understood. It has been demonstrated that a delay in gastric emptying may determine a delay in GI transit (17). In fact, we have reported that BV expansion delays the gastric emptying of liquid in awake rats $(14,16)$. However, changes in small intestine transit time can occur independently of changes in gastric emptying (17) and the rate of gastric emptying can influence the transit of food down the first $70 \mathrm{~cm}$ of the human intestine, but have little or no influence down the entire small intestine in normal subjects (17).

In this respect, GI transit delay due to BV expansion may not be essentially determined by a gastric emptying delay, since BV expansion modifies jejunal compliance (10) and in animals submitted to fundectomy, BV expansion also did not delay gastric emptying, while the final GI transit was markedly delayed, thus indicating the activation of small bowel resistance by BV expansion (14).

Subdiaphragmatic vagotomy prevented the effect of BV expansion on GI transit. These findings indicate that vagal pathways are necessary for the full expression of the phenomenon. However, the effect of vagotomy may be incomplete since we still observed a tendency to a delay in GI transit after BV expansion in animals submitted to subdiaphragmatic vagotomy. Cholinergic pathways appear not to be involved since atropine did not block the effect of BV expansion on GI transit. L-NAME was also unable to prevent the effect of BV expansion on GI transit.

Yohimbine (an $\alpha_{2}$ antagonist) prevented the effect of BV expansion on GI transit, while hexamethonium (a ganglion blocker), propranolol (a $\beta$ blocker) and prazosin (an $\alpha_{1}$ antagonist) were ineffective. Alpha- 2 receptors are located both in the central nervous system and peripherally (18). Our find-
Table 2 - Effect of drug pretreatment on mean arterial pressure (MAP) before and after $5 \%$ blood volume expansion (EXP) with iv infusion of Ringer-bicarbonate, $1 \mathrm{ml} / \mathrm{min}$.

The number of animals is given within parentheses. ${ }^{*} \mathrm{P}<0.05$ compared to basal MAP levels (Student-Newman-Keuls test).

\begin{tabular}{lcc} 
Treatment & \multicolumn{2}{c}{ MAP } \\
\cline { 2 - 3 } & Before EXP & After EXP \\
\hline Atropine $(0.5 \mathrm{mg} / \mathrm{kg})$ & $100.1 \pm 3.6$ & $102.2 \pm 3.9(5)$ \\
L-NAME $(2 \mathrm{mg} / \mathrm{kg})$ & $142.6 \pm 5.6^{*}$ & $148.4 \pm 3.8^{*}(5)$ \\
Hexamethonium $(10 \mathrm{mg} / \mathrm{kg})$ & $72.1 \pm 3.4^{*}$ & $80.1 \pm 4.2^{*}(5)$ \\
Yohimbine $(3 \mathrm{mg} / \mathrm{kg})$ & $98.1 \pm 4.4$ & $96.3 \pm 4.2(4)$ \\
Prazosin $(1 \mathrm{mg} / \mathrm{kg})$ & $70.2 \pm 3.4^{*}$ & $82.1 \pm 4.2^{*}(4)$ \\
Propranolol $(2 \mathrm{mg} / \mathrm{kg})$ & $82.4 \pm 3.4^{*}$ & $87.1 \pm 4.2^{*}(4)$
\end{tabular}

ings suggest that central rather than peripheral $\alpha_{2}$ receptors are activated by BV expansion, since peripheral activation would be associated with an increased sympathetic activity and thus would be blocked by hexamethonium and/or by prazosin and propranolol. Central $\alpha_{2}$ activation causes a significant decrease in sympathetic activity (19), similar to that observed after BV expansion (20), and mediates GI motility inhibition (18). However, it has been demonstrated that yohimbine can also modulate vagal activity and act upon non-adrenergic receptors (21).

Our findings point to an involvement of neural pathways. However, increased CVP also leads to a release of several hormones and autacoids, such as the atrial natriuretic peptide (ANP), which could interfere with GI motility, absorption and secretion. In fact, it has been demonstrated that ANP can increase the magnitude of spontaneous duodenal phasic contractions (22) and reduces fluid and electrolyte intestinal absorption (23).

Hepatorenal and hepatointestinal reflex systems are of paramount importance for $\mathrm{Na}^{+}$and ultimately liquid homeostasis (24). BV expansion causes important homeostatic modifications to manage increased body liquid volume and attain a new steady state. Diuretic and natriuretic responses following BV expansion have been extensively studied (25), as well as decreased intestinal sodium/ 
water absorption and increased secretory rates (6). Even subtle postural changes (tilting and standing up) simulating BV changes might modify intestinal salt and water permeability rates in man (26).

Since GI motility is related to absorption and secretion (8), the delay in GI transit of liquid observed here, taken together with the absorptive and secretory modifications de- scribed by others $(5,6)$, may be part of the body strategies involved in the management of liquid excess.

\section{Acknowledgments}

We thank Fernando Antonio A. Gondim and R. Fogaça for statistical support and Dr. G.B. Viana for providing research facilities.

\section{References}

1. Sawchenko PE \& Fridman MI (1979). Sensory functions of the liver. American Journal of Physiology, 236: R5-R20.

2. Michel AR (1986). The gut: the unobtrusive regulator of sodium balance. Perspectives in Biology and Medicine, 29: 203213.

3. Guyton A \& Hall J (1996). Digestion and absorption in the gastrointestinal tract. In: Textbook of Medical Physiology. 9th edn. W.B. Saunders, Philadelphia, PA, 833-851.

4. Miller WL \& Dale HE (1978). Restoration of hemorrhaged plasma volume by gastrointestinal fluid in the dog. American Journal of Physiology, 234: H80-H87.

5. Duffy PA, Granger DN \& Taylor AE (1978). Intestinal secretion induced by volume expansion in the dog. Gastroenterology, 75: 413-418.

6. Levens NR (1985). Control of intestinal absorption by the renin-angiotensin system. American Journal of Physiology, 249: G3-G15.

7. Suzuki S, Khanchowdhury MR, Uemura N, Morita H \& Hosomi H (1992). Renojejunal reflex controlling jejunal absorption of fluid and $\mathrm{NaCl}$. Journal of the Autonomic Nervous System, 39: 219-228.

8. Lee JS (1983). Relationship between intestinal motility, tone, water absorption and lymph flow in the rat. Journal of Physiology, 345: 489-499.

9. Capelo LR, Cavalcante DM, Leitão IA, Cristino Filho G \& da-Silva EAT (1983). Modifications of gastric compliance in dogs related to changes of extracellular fluid volume. Brazilian Journal of Medical and Biological Research, 16: 73-76.

10. Rola FH, dos-Santos AA, Xavier-Neto J, Cristino-Filho G, Rocha Cl, Santiago Jr AT, Gondim FAA, Pereira JM \& Capelo LR (1989). Effects of acute volemic changes on the jejunal compliance in dogs. Brazilian Journal of Medical and Biological Research, 22: 523-531.
11. Santos AA, Xavier-Neto J, Santiago Jr AT, Souza MAN, Martins AS, Alzamora $F$ \& Rola FH (1991). Acute volaemic changes modify the gastroduodenal resistance to the flow of saline in anaesthetized dogs. Acta Physiologica Scandinavica, 143: 261269.

12. Xavier-Neto J, Dos Santos AA \& Rola FH (1990). Acute hypervolemia increases the gastroduodenal resistance to the flow of saline in rats. Gut, 31: 1006-1010.

13. Green AF (1959). Comparative effects of analgesics on pain threshold, respiratory frequency and gastrointestinal propulsion. British Journal of Pharmacology, 14: 2634.

14. Rego MCV, da-Graça JRV, Gondim F deAA, Gondim RB de-M, Dantas RP \& Rola FH (1998). Effect of pyloroplasty and fundectomy on the delay of gastric emptying and gastrointestinal transit of liquid elicited by acute blood volume expansion in awake rats. Brazilian Journal of Medical and Biological Research, 31 (in press).

15. Santiago Jr AT, Gondim F de-AA, Cavalcante DIM, da-Graça JRV, deOliveira GR, dos-Santos AA \& Rola FH (1997). Acute extracellular fluid volume changes increase ileocolonic resistance to saline flow in anesthetized dogs. Brazilian Journal of Medical and Biological Research, 30: 999-1008.

16. Gondim FAA, Oliveira GR, Graça JRV, Cavalcante RBM, Gondim DIM, Santiago Jr AT \& Rola FH (1996). Gastrointestinal motor reflexes elicited by acute blood volume expansion in awake rats. Neurogastroenterology and Motility, 8: 168 (Abstract).

17. Read NW, Cammack J, Edwards C, Holgate AM, Cann PA \& Brown C (1982). Is the transit time of a meal through the small intestine related to the rate at which it leaves the stomach? Gut, 23: 824-828.

18. Fargeas MJ, Fioramonti $\mathrm{J} \&$ Bueno $\mathrm{L}$
(1986). Central alpha-2 adrenergic control of the pattern of small intestinal motility in rats. Gastroenterology, 91: 1470-1475.

19. Klangkalya B, Sripairojthikoon W, Oparil S \& Wyss JM (1988). High $\mathrm{NaCl}$ diet increases anterior hypothalamic alpha-2 adrenoceptors in SHR. Brain Research, 451: 77-84.

20. Ricktsen SE \& Thoren P (1980). Reflex inhibition of sympathetic activity during volume load in awake normotensive and spontaneously hypertensive rats. Acta Physiologica Scandinavica, 110: 77-82.

21. Trostel KA, Kata SA \& Osborn JW (1994) Does the spinal cord generate significant sympathetic activity in the awake rat? American Journal of Physiology, 266: R1102-R1110.

22. Bayens DA, Walters JM \& Vesely DL (1988). Atrial natriuretic factor increases the magnitude of duodenal spontaneous phasic contractions. Biochemical and Biophysical Research Communications, 155: 1437-1443.

23. Matshushita K, Nishida $Y$, Hosomi H \& Tanaka S (1991). Effects of atrial natriuretic peptide on water and $\mathrm{NaCl}$ absorption across the intestine. American Journal of Physiology, 260: R6-R12.

24. Hosomi H \& Morita H (1996). Hepatorenal and hepatointestinal reflexes in sodium homeostasis. News in Physiological Sciences, 11: 103-107.

25. Wardener HE, Mills IH, Clapham WF \& Hayter CJ (1961). Studies on the efferent mechanism of the sodium diuresis which follows the administration of intravenous saline in the dog. Clinical Science, 21: 249-258.

26. Sjovall $\mathrm{H}$, Abrahamsson $\mathrm{H}$, Westlander $\mathrm{G}$ Gillberg R, Redfords S, Jodal M \& Lundgren O (1986). Intestinal fluid and electrolyte transport in man during reduced circulating blood volume. Gut, 27: 913-918. 